\title{
A pedigree analysis with minimised ascertainment bias shows anticipation in Met30-transthyretin related familial amyloid polyneuropathy
}

\author{
Kanji Yamamoto, Shu-ichi Ikeda, Norinao Hanyu, Shin'ichi Takeda, Nobuo Yanagisawa
}

\begin{abstract}
In type I familial amyloid polyneuropathy (FAP) caused by a variant Met30transthyretin (TTR), genetic anticipation has been reported. To determine whether anticipation of the disease is a true biological phenomenon or the result of ascertainment bias, we compared age at onset of the affected child with that of the affected parent in 68 parent-child pairs (including data on assumed age at onset and on asymptomatic obligate heterozygotes and parents at obligate $50 \%$ risk) in 15 families. Excluding the parent-child pairs involving the proband and "bilineal pairs", onset occurred earlier in the child than in the transmitting parent in 60 out of 68 "unilineal pairs". After correction for ascertainment bias resulting from incomplete penetrance and reduced biological fitness in early onset patients, the number of anticipation pairs (60 pairs) was still significantly larger than that of nonanticipation pairs $(29.7$ pairs $)(p<0.05)$. When the children were sons, the difference in age at onset was significantly greater in the mother-son pairs than in the father-son pairs $(p=0.023)$. Although not all ascertainment biases could be eliminated, these data show strong evidence that anticipation in the transmission of Met30-TTR FAP is a true biological phenomenon. $(\mathcal{M}$ Med Genet 1998;35:23-30)
\end{abstract}

Keywords: familial amyloid polyneuropathy; transthyretin; anticipation; ascertainment bias

Neurology, Nagan Red Cross Hospital, Nagano 380, Japan N Hanyu

Department of Molecular Genetics, National Institute of Neuroscience, National Centre of Neurology and Psychiatry,

Kodaira, Tokyo 187, Japan

$S$ Takeda

Correspondence to: Dr Yamamoto, Department of Molecular Genetics, National Institute of Neuroscience, National Center of Neurology and Psychiatry, Kodaira, Tokyo 187, Japan.

Received 21 January 1997 Revised version accepted for publication 21 July 1997

The transthyretin (TTR) amyloidoses are the most prevalent type of hereditary systemic amyloidoses exhibiting an autosomal dominant pattern. ${ }^{12}$ Peripheral neuropathy is the major clinical manifestation of some TTR amyloidoses, and the syndrome is named familial amyloid polyneuropathy (FAP). There are now approximately 60 known variants of TTR. ${ }^{2} \mathrm{~A}$ disorder caused by a variant TTR with a substitution of methionine for valine at position 30 (Met30-TTR) $^{3}$ causes a lethal systemic amyloidosis characterised by progressive polyneuropathy and autonomic failure. The disorder has to date been called type I FAP. This type of TTR amyloidosis is the most common and patients are widely distributed in the world. ${ }^{4}$ The age at onset of type I FAP is variable, ranging from the second decade to the seventh decade and penetrance is incom- plete. ${ }^{56}$ Thus, some unknown factor(s), environmental or genetic or both, other than the Met30-TTR mutation is involved in determination of the age at onset.

The clinical observation of anticipation, which means earlier onset and a more severe clinical picture in successive generations, has been noted in a number of hereditary disorders, such as Huntington's disease (HD), ${ }^{7}$ myotonic dystrophy (DM), ${ }^{8}$ spinocerebellar ataxia type 1 (SCA1), ${ }^{9}$ bipolar affective disorder, ${ }^{10}$ polycystic kidney disease, ${ }^{11}$ leukaemia, ${ }^{12}$ and facioscapulohumeral muscular dystrophy. ${ }^{13}{ }^{14}$ In some of these (including $\mathrm{HD}, \mathrm{DM}$, and SCA1), increasing size of a trinucleotide repeat in successive generations is presumed to be the molecular basis for the anticipation. ${ }^{15}$ An anticipation phenomenon has also been reported in type I FAP patients originating from Portuguese, ${ }^{16-18}$ Swedish, ${ }^{19}$ and some Japanese (Kumamoto prefecture and its vicinity ${ }^{20}$ kindreds, but ascertainment bias such as described by Penrose ${ }^{21}$ for DM was not sufficiently eliminated in these reports. In contrast to "triplet repeat diseases", one base substitution in the TTR gene is responsible for the development of Met30-TTR FAP or type I FAP, and this gene abnormality cannot solely explain the anticipation. It is, therefore, important to clarify whether the anticipation in Met30-TTR FAP is a true biological phenomenon or a result of ascertainment bias. In the present study, we suggest that anticipation in the FAP families with a Met30-TTR gene abnormality may really occur.

\section{Materials and methods}

FAMILIES AND CLINICAL DIAGNOSIS

There are two large foci of type I FAP in Japan:
Kumamoto $^{22}$ and Nagano prefectures. ${ }^{23}{ }^{24}$ Our study was performed on families in Nagano prefecture and its vicinity. The subjects were diagnosed as having type I FAP on the basis of the following criteria: (1) positive family history; (2) clinical symptoms or signs suggesting an early stage of type I FAP, such as intolerable burning and shooting pains or loss of pain sensation in the legs or both, orthostatic faintness, impotence, uncontrollable constipation or diarrhoea, and arrhythmia (some symptoms such as slight numbness and mild constipation or diarrhoea were difficult to classify as specific symptoms of the disease and were excluded from this criterion); (3) amyloid deposition in biopsy or necropsy tissues.

We initially ascertained 94 subjects between 1974 and 1995 satisfying all three criteria as definite patients with type I FAP. They 
belonged to 52 families and included 52 probands. In 1990 we started to investigate TTR gene abnormalities including the Met30TTR mutation using a PCR-RFLP method reported elsewhere. ${ }^{4}$ We had verified the Met30-TTR mutation in 47 (including two patients homozygous for this mutation ${ }^{25}$ ) out of 94 patients, and additionally in five other patients (all heterozygous for the mutation) who were not diagnosed as type I FAP because they had satisfied criteria (2) and (3) but not criterion (1) (patients with "sporadic" type I FAP). The remaining patients did not undergo DNA analysis because they had moved to other hospitals or had died before 1990. In this way we obtained 38 families, in which at least one patient proved to have the Met30-TTR mutation.

DETERMINATION OF AGE AT ONSET AND

VERIFYING ANTICIPATION

In these 38 families we carefully interviewed family members to collect information on their type I FAP affected relatives, especially on the ages at onset, symptoms, and ages at death if relevant, and we examined them if they were alive. The age when the patients showed any of the initial symptoms of type I FAP (criterion (2) mentioned above) was identified as the age at onset.

At first, according to the confirmed data, we compared the age at onset of the affected child with that of the affected parent in each parentchild pair, considering the following two points. (1) Since patients with early onset disease tend to die at a relatively early age, these patients would not be represented in a survey of older patients. Conversely, young patients with late onset might not show any signs or symptoms and would not come to medical attention. To compensate for this tendency, we tried to examine large families in which we could obtain many patients with type I FAP and excluded the parent-child pairs involving the proband. (2) Those pairs with a child born to consanguineous parents, that is, "bilineal pairs", were excluded, because the additive effect from homozygosity for the Met30-TTR mutation or other loci might create the appearance of anticipation.

Next, in the patients whose age at death only was available, their ages at onset were assumed from the mean duration of survival after onset of our type I FAP patients, as shown in table 1. The probands and sporadic patients were included in this table, but the patients who clearly died of causes other than the natural course of the disease, such as suicide or infections after liver transplantation, were excluded. In female patients who died at ages 40 49, 50 59, and 60 , we obtained the ages at onset after subtracting 13,10 , and 9 , respectively, from each age at death. In female patients who died at age 30 39, we arbitrarily obtained the ages at onset after subtracting 13 from each age at death. In male patients who died at ages $30 \sim 39,40 \sim 49,50 \sim 59$, and 60 , the ages at onset were obtained after subtracting $9,9,11$, and 12 , respectively, from each person's age at death.
Furthermore, for asymptomatic obligate heterozygotes or ancestors at obligate $50 \%$ risk whose offspring were affected, if information was available, we incorporated their data into the analysis.

\section{ALLEVIATION OF ASCERTAINMENT BIAS}

There are some possible ascertainment biases that could explain results indicating anticipation. $^{21}$ First, ascertainment bias can follow from the variable age at onset of the phenotype in patients with the Met30-TTR mutation. Since the penetrance of the disease is likely to be incomplete among the children of our families, and subjects in recent generations may have been too young to express a late onset form of type I FAP at the time of this study (in 1995), late onset disease may have been missed in those who are categorised as unaffected. To alleviate this ascertainment bias, we calculated the number of unaffected persons who had a probability of suffering from the disease, as described in detail in the Results section.

Second, ascertainment bias may also be caused by reduced biological fitness of early onset patients who would tend to produce few children. To compensate for this bias, the number of additional children who would have been born to the patients with early onset if they had had normal fertility was estimated, as also described in detail in the Results section.

\section{STATISTICAL ANALYSES}

We calculated the difference in ages at onset between the females and the males, using Student's $t$ test. The difference in age at onset between the parents and the children was calculated and to ascertain the significance of the observed anticipation, a chi-square test for goodness of fit was used. Between unilineal and bilineal pairs, the differences in age at onset between the parents and the children were compared, using two sample $t$ test with Welch's correction. Furthermore, the differences in age at onset between the parents and the children were compared between groups divided according to the sex of the parent or child, using Student's $t$ test.

\section{Results}

AGE AT ONSET IN PARENT-CHILD PAIRS AND ANTICIPATION

We tried to examine all 38 families, each of them including at least one patient with the Met30-TTR mutation. However, it soon became clear that it was impossible to obtain sufficiently large pedigrees for all families, since many members lived too far from Nagano prefecture, refused to cooperate, or had died. Moreover, it was very difficult to confirm the ages at onset of patients who died many years

Table 1 The mean survival after onset of symptoms estimated from available data of all type I FAP patients

\begin{tabular}{lll}
\hline Age at death $(y)$ & Female & Male \\
\hline $30 \sim 39$ & $-(\mathrm{n}=0)$ & $9.0(\mathrm{n}=5)$ \\
$40 \sim 49$ & $13.3(6)$ & $9.0(8)$ \\
$50 \sim 59$ & $9.8(8)$ & $10.8(4)$ \\
$60 \sim$ & $8.5(6)$ & $12.2(5)$ \\
Total & $10.5(20)$ & $10.0(22)$ \\
\hline
\end{tabular}




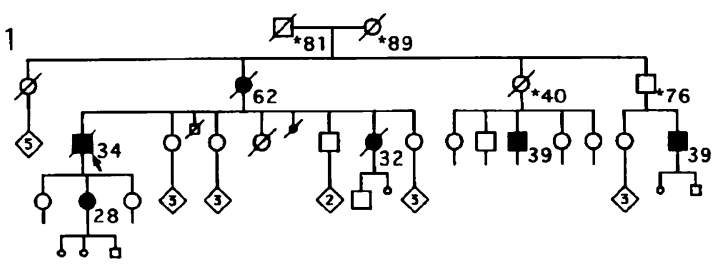

3
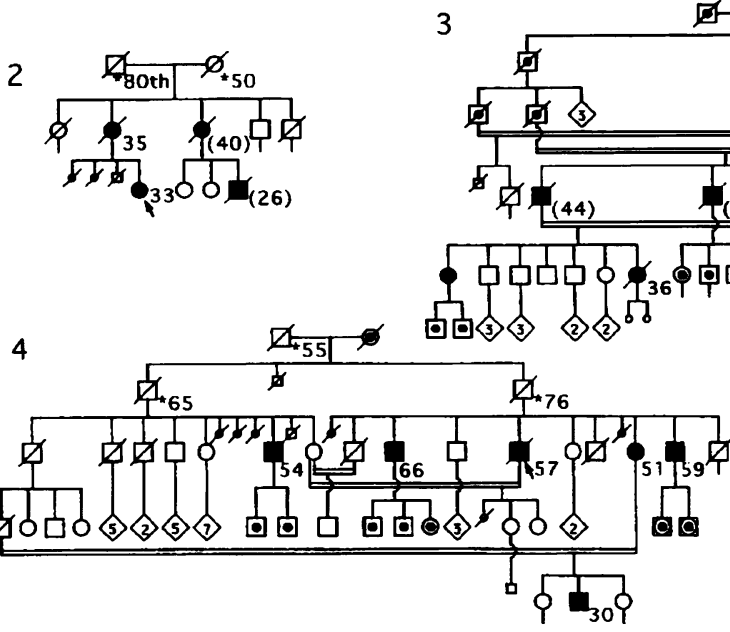

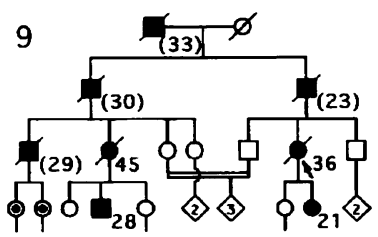

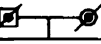

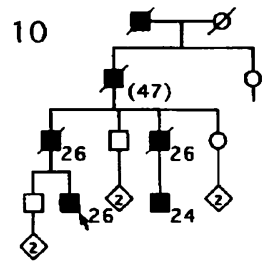

5

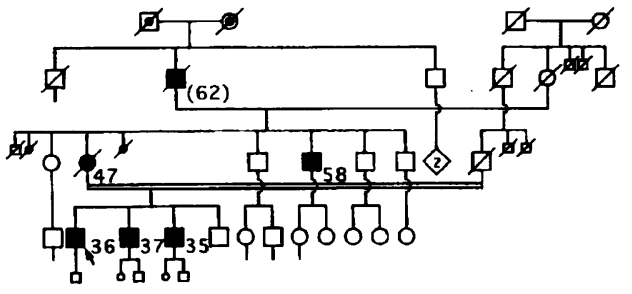

6

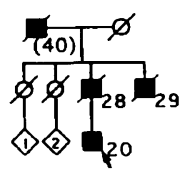
(1) 220

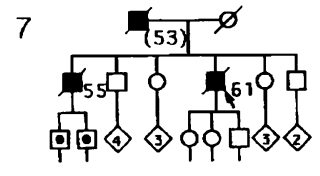

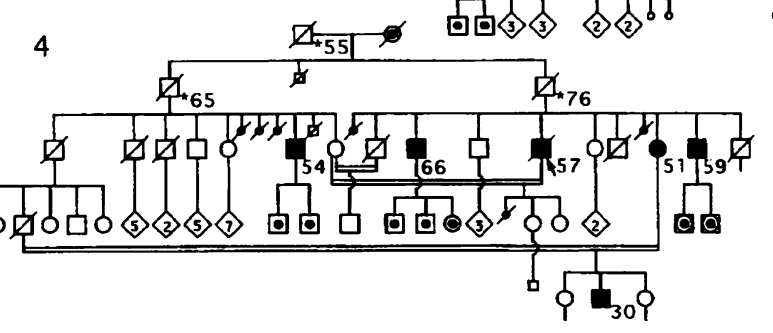
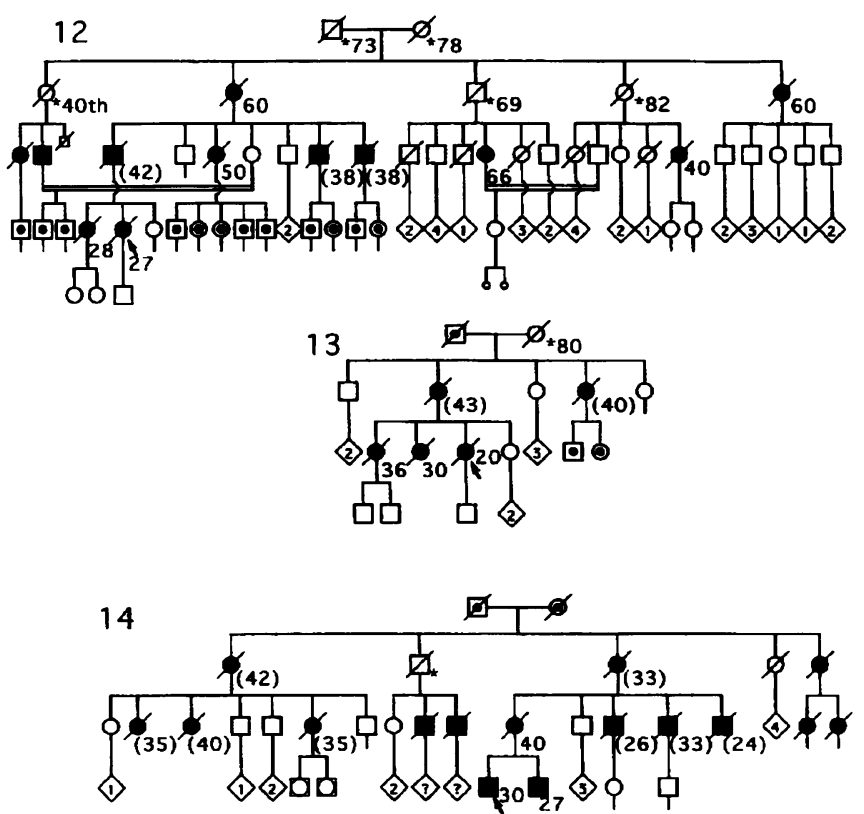

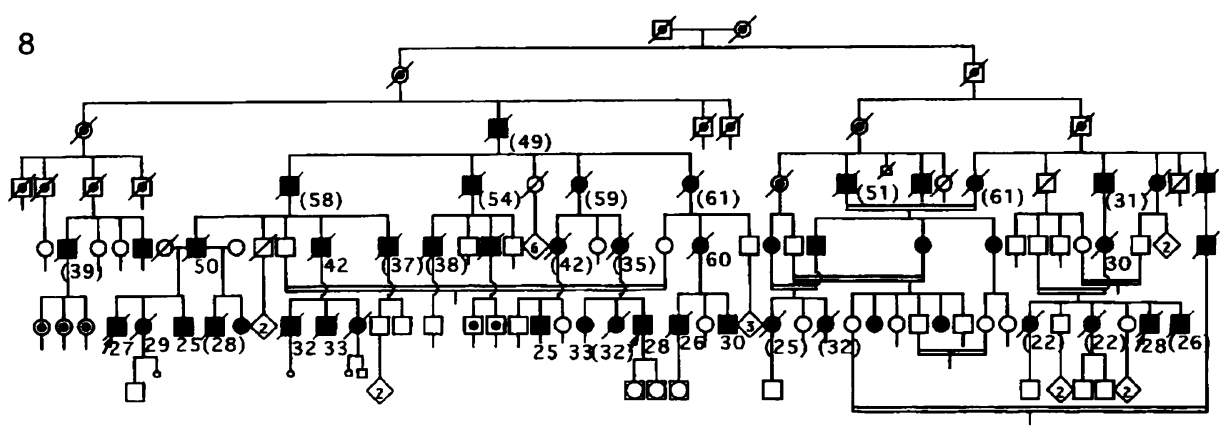

15

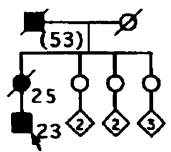

Affected female and male. Number beside affected subject shows the age at onset. Presumed age at onset is shown in brackets

- $\square$ Subject under 20 years of age

ㅁ Normal, the children not examined

○ Lack of sufficient information on disease expression

a Unknown gender

(3) 3 sibs

- Proband

ㅁ. Asymptomatic obligate heterozygote or asymptomatic ancestor at obligate $50 \%$ risk. Number beside asterisk shows present age or age at death 
Table 2 Analysis of age at onset in affected parent-child pairs with Met30-TTR FAP. A $\chi^{2}$ goodness of fit test was used to ascertain the significance of the observed anticipation

\begin{tabular}{|c|c|c|c|c|}
\hline & \multicolumn{2}{|l|}{ Age at onset } & \multirow[b]{2}{*}{$\chi^{2}$} & \multirow[b]{2}{*}{$p$} \\
\hline & Parent $>$ child & Parent $\leqslant$ child & & \\
\hline $\begin{array}{l}\text { (A) Age at onset verified parent-child pairs excluding the pairs } \\
\text { involving the probands }\end{array}$ & 11 & 0 & 7.33 & $<0.01$ \\
\hline (B) Adding data assumed from the age at death & 47 & 8 & 15.82 & $<0.001$ \\
\hline $\begin{array}{l}\text { (C) Adding data of asymptomatic obligate heterozygotes and } \\
\text { parents at obligate } 50 \% \text { risk }\end{array}$ & 60 & 8 & 23.29 & $<0.001$ \\
\hline $\begin{array}{l}\text { (D) Eliminating ascertainment bias owing to incomplete } \\
\text { penetrance }\end{array}$ & 60 & 15 & 14.84 & $<0.001$ \\
\hline $\begin{array}{l}\text { (E) Eliminating ascertainment bias owing to reduced biological } \\
\text { fitness in early onset patients }\end{array}$ & 60 & 29.7 & 5.27 & $<0.05$ \\
\hline
\end{tabular}

ago, even if we had information on their ages at death, because their relatives could not recall the precise year of the patients' onset of symptoms. In addition, since it was, at the earliest, after 1968 that the disease entity of FAP was recognised in Japan, ${ }^{22}$ almost no medical records of patients of older generations were useful.

Finally, we were able to obtain information on 15 families which included many patients with verified or presumed age at onset (fig 1). These families did not include two patients homozygous for the Met30-TTR mutation, because no apparent symptoms had developed in their parents and children. ${ }^{25}$ Since the pedigree study proved that ancestors of three probands were related to one another (in family 8), the 15 families included 17 probands. Comparing the data on the probands of these families ( $n=17$, five females and 12 males) with those on the probands of all the other type I FAP families (including probands in whom the Met30-TTR mutation was not verified, $n=35$, 13 females and 22 males) excluding sporadic patients, no significant difference was found for age at onset (mean 33.8 years (SD 12.9), mean 38.1 years (SD 11.7), Student's $t$ test, $\mathrm{p}=0.121)$ or sex $\left(\mathrm{df}=1, \chi^{2}=0.302\right)$. However, mean age at onset of sporadic patients $(n=5$, three females and two males, mean $\mathbf{5 7 . 2}$ years (SD 9.7)) was higher than that of the other two groups.

In these 15 families, ages at onset were verified in 69 patients (28 females and 41 males) including 17 probands. The ages at onset were not significantly different $(p=0.094)$ between females (mean 40.0 years (SD 13.6)) and males (mean 35.8 years (SD 12.2)). Twentyone unilineal pairs of an affected parent with an affected child were identified, and then 10 parent-child pairs involving the proband were excluded. In the remaining 11 unilineal pairs, all children had an earlier onset than their transmitting parent (table 2A). In only one out of 11 pairs was the difference in age at onset within two years. The mean difference in age at onset (parent's age at onset minus child's age at onset) was 18.3 (SD10.5) years (range +2 34 years).

Adding data assumed from the age at death, the ages at onset were available in 116 patients (47 females and 69 males, range $20 \sim 66$ years) in 15 families. The ages at onset were also not significantly different $(\mathrm{p}=0.131)$ between females (mean 39.8 years (SD 12.8)) and males (mean 37.2 years (SD 11.8)) (the probands were included). We identified 70 unilineal and 11 bilineal affected parent-child pairs. Excluding 15 pairs involving a proband from unilineal pairs, we were left with 55 unilineal pairs. In 47 out of 55 unilineal pairs (85.5\%), the children had an earlier onset than their transmitting parent (table 2B). In six of 47 pairs, the difference in age at onset was within two years (in six pairs, ages at onset of five parents and two children were assumed). The mean difference in age at onset was 10.7 years (SD 11.1) (range $-15 \sim+34$ years). In eight bilineal pairs which did not involve probands, all children had an earlier onset than their transmitting parent. The mean difference in age at onset was 10.0 years (SD 4.4) (range $+4 \sim 19$ years). Between unilineal and bilineal pairs, no significant difference was found for the differences in age at onset between parents and children $(\mathrm{p}=0.373)$.

Furthermore, incorporating asymptomatic obligate heterozygotes into the analysis (one of them was alive and the others were dead), eight pairs with affected offspring apart from probands could be added. Since the present age of the living parent or age at death of the dead parent was higher than the age at onset of the affected child in each pair, we regarded these eight pairs as showing anticipation. Three couples of ancestors at obligate $50 \%$ risk, who had been asymptomatic through life and had died of other causes, had five affected children. The ages at death of both parents were higher than the age at onset of the child in all cases, so that five further pairs showing anticipation were added. Thus, we found a significantly larger number of pairs showing anticipation than those that did not (table $2 \mathrm{C}, \chi^{2}=23.29$, $\mathrm{p}<0.001$ ).

\section{ALLEVIATION OF ASCERTAINMENT BIAS}

To alleviate ascertainment bias owing to incomplete penetrance, we calculated the number who had a probability of suffering from type I FAP in unaffected children of 20 years of age or over. (Since there were no patients with age at onset less than 20 in our series of type I FAP patients, we regarded 20 years as a minimum age of risk for the disease in this study.) We applied DNA analysis to three members of unaffected unilineal children with affected parents (excluding the offspring of the proband). One of them had the Met30TTR mutation and two did not. On other unilineal children of affected parents whose ages at onset were verified or assumed, we estimated 
Table 3 Ascertainment categories and inclusion in segregation analysis

\begin{tabular}{llll}
\hline Category & Ascertainment & $\begin{array}{l}\text { Inclusion in } \\
\text { segregation analysis }\end{array}$ & Entries required \\
\hline A & Proband & - & - \\
B & Affected parent or grandparent of proband & + & Single \\
C & Offspring of proband & - & - \\
D & Offspring of previously known affected relative & + & Single \\
E & Sib of proband or of affected parent & + & Single \\
F & Sib of an affected subject, whose affected status proves parent to be an & + & Multiple \\
G & obligate heterozygote, or proves dominant inheritance & Double \\
H & Obligate heterozygote & + & - \\
\hline
\end{tabular}

Table 4 Reduced biological fitness in early onset patients

\begin{tabular}{|c|c|c|c|c|c|c|c|c|}
\hline \multirow[b]{3}{*}{ Age at onset } & \multicolumn{4}{|c|}{ Born after 1915} & \multicolumn{4}{|c|}{ Born in or before 1915} \\
\hline & \multicolumn{2}{|c|}{ Females } & \multicolumn{2}{|c|}{ Males } & \multicolumn{2}{|c|}{ Females } & \multicolumn{2}{|c|}{ Males } \\
\hline & No & $\begin{array}{l}\text { Mean No of } \\
\text { children }\end{array}$ & No & $\begin{array}{l}\text { Mean No of } \\
\text { children }\end{array}$ & No & $\begin{array}{l}\text { Mean No of } \\
\text { children }\end{array}$ & No & $\begin{array}{l}\text { Mean No of } \\
\text { children }\end{array}$ \\
\hline $20 \sim 24$ & 2 & 1.50 & 1 & 0.00 & 0 & - & 1 & 3.00 \\
\hline $25 \sim 29$ & 4 & 1.50 & 7 & 1.17 & 0 & - & 0 & - \\
\hline $30 \sim 34$ & 4 & 0.00 & 1 & 1.00 & 1 & 5.00 & 3 & 2.33 \\
\hline $35 \sim 39$ & 5 & 1.60 & 4 & 1.75 & 0 & - & 1 & 3.00 \\
\hline $40 \sim 44$ & 5 & 2.00 & 1 & 3.00 & 3 & 4.33 & 2 & 3.50 \\
\hline $45 \sim 49$ & 1 & 3.00 & 1 & 4.00 & 0 & - & 2 & 4.50 \\
\hline $50 \sim 54$ & 1 & 5.00 & 1 & 2.00 & 0 & - & 4 & 4.75 \\
\hline $55 \sim 59$ & 0 & - & 3 & 2.00 & 1 & 3.00 & 1 & 5.00 \\
\hline $60 \sim 64$ & 1 & 3.00 & 0 & - & 4 & 5.50 & 1 & 6.00 \\
\hline $65 \sim 69$ & 0 & - & 0 & - & 0 & - & 1 & 3.00 \\
\hline $20 \sim 39$ & 15 & 1.31 & 13 & 1.25 & 1 & 5.00 & 5 & 2.60 \\
\hline $40 \sim 69$ & 8 & 2.63 & 6 & 2.50 & 8 & 4.75 & 11 & 4.45 \\
\hline Total & 23 & 1.81 & 19 & 1.67 & 9 & 4.78 & 16 & 3.88 \\
\hline Normal sibs & 27 & 2.04 & 30 & 2.00 & 15 & 4.33 & 25 & 3.80 \\
\hline
\end{tabular}

the segregation ratio and the number of asymptomatic carriers of the Met30-TTR mutation. In estimating the segregation ratio, we categorised the unilineal children according to the route of their individual ascertainment of at risk status (table 3 ) to minimise ascertainment bias. ${ }^{26}$ We included those who had died, who were ascertained to be affected or not. In this segregation analysis, we found 62 affected and 74 unaffected children. Assuming that half of these 136 children ( 68 children) had the Met30-TTR mutation, the number of asymptomatic children with the mutation was estimated to be six. Then, adding the child proven to have the mutation by DNA analysis, we obtained seven complementary parent-child pairs. If all seven children should have a later onset in life than their parent, we would obtain 60 anticipation pairs and 15 non-anticipation pairs (table 2D).

To account for ascertainment bias owing to reduced biological fitness in early onset patients, the number of additional children who would have been born to such patients if they had had normal fertility was estimated, using the average number of children born to unaffected sibs in 15 families (table 4). This was tested on the females born before 1948 and the males born before 1945, whose children's mean age would have been 20 years or over in 1995 . Since the number of children per head of the Japanese population decreased considerably after World War II, we divided the patients and unaffected sibs into two groups by the year of birth (after 1915 and in or before 1915). When the age at onset was 40 years or over, the fertility of female and male patients was higher than that of the normal sibs in both groups, but below 40 years, it was lower except for a female patient who was born in or before 1915. Fifteen female patients who were born after 1915 and had an onset below 40 would have had 13.6 more children if their fertility had been normal: $((2.04-1.50) \times 2+(2.04-$

$1.50) \times 4+2.04 \times 4+(2.04-1.60) \times 5)$. Similarly, in the males with an onset below 40 years, 13 patients who were born after 1915 would have had 9.8 more children: $(2.00 \times 1+(2.00-$ $1.17) \times 7+(2.00-1.00) \times 1+(2.00-1.75) \times 4)$, and five patients who were born in or before 1915 would have had 6.0 more children: ( $(3.80-$ $3.00) \times 1+(3.80-2.33) \times 3+(3.80-3.00) \times 1)$.

Thus, assuming normal fertility, the other 29.4 children would have been born into these families, and half of them (14.7 children) would have carried the abnormal gene. If disease onset in these additional children occurred randomly, since the age at onset of their parents was relatively low (below 40), most of the parent-child pairs could be classified as non-anticipation pairs. Thus, we added 14.7 pairs to the non-anticipation pairs (table 2E). After correction of bias, the number of anticipation pairs was still significantly larger than that of non-anticipation pairs with chisquare test for goodness of fit $\left(\chi^{2}=5.27\right.$, $\mathrm{p}<0.05$ ).

SEX INFLUENCE

In table 5 the differences in age at onset are recorded according to the sex of parents and children (including data assumed from the age at death). The mean difference in ages at onset was greater in the pairs with a transmitting mother than in the pairs with a transmitting father, but not significantly (Student's $t$ test, $p=0.082$ ). When the children were sons, however, the difference in age at onset was sig- 
Table 5 Affected parent-child pairs and differences in ages at onset according to sex

\begin{tabular}{llll}
\hline & No of pairs & $\begin{array}{l}\text { Mean difference in } \\
\text { ages at onset }\end{array}$ & $\begin{array}{l}\text { Range of differences in } \\
\text { ages at onset }\end{array}$ \\
\hline Mother-daughter & 13 & +8.9 & $-7 \sim+30$ \\
Mother-son & 13 & +16.9 & $0 \sim+34$ \\
Father-daughter & 8 & +5.3 & $-15 \sim+28$ \\
Father-son & 21 & +10.0 & $-9 \sim+25$ \\
Total & 55 & +10.7 & $-15 \sim+34$ \\
\hline
\end{tabular}

nificantly greater in the mother-son pairs than in the father-son pairs $(p=0.023)$. Furthermore, the difference in age at onset was significantly greater on transmission to sons than to daughters $(p=0.048)$.

\section{Discussion}

Our study showed that the anticipation observed in type I Met30-TTR FAP families in Japan cannot be solely explained by ascertainment bias. However, some points should be considered in this study before drawing a conclusion.

First, although in 69 patients the age at onset was decided on the basis of objective findings or subjective histories or both, in 47 other patients the age at onset was assumed from the age at death. Did this assumption cause a bias towards the result of anticipation? In our study, most of the patients for whom we could verify the age at onset were in relatively young generations and most of the patients whose age at onset could not be verified were in relatively old generations. Since the duration of survival after onset of type I FAP has generally become longer because of advances in treatment, in most of the patients for whom we could not verify the age at onset, the actual age at onset may have been higher than that assumed from age at death. Indeed, in the examination of the parent-child pairs with verified age at onset, all children fell ill earlier in life than their transmitting parent (table 2A). Compared to this, with the addition of assumed data, some children had a later onset than their affected parent (table 2B) and the mean difference in age at onset between the parents and children became smaller. Accordingly, assuming the age at onset does not seem to be responsible for the result that substantiated the anticipation.

Second, as age at onset was later in life, the mean duration of survival after onset was shorter in female patients, but longer in male patients (table 1). Although the biological reason for this phenomenon is unclear, it does not seem that the use of the figures from table 1 raises the relative proportion of anticipation pairs.

Third, Met30-TTR gene carriers in younger generations who already had affected relatives in older generations may often have noticed slight and non-specific symptoms and may have detected these as initial symptoms of the disease. However, we did not recognise such slight and non-specific symptoms as onset of the disease (mentioned in Materials and methods section). Considering that the mean duration of survival of type I FAP was about 10 years (table 1), progression of the disease is generally rapid and steady. Therefore, there seems to be no large error in deciding the age at onset and we assumed the error was at most two years. Adding assumed ages at onset, the difference in age at onset between parents and children was within two years in six of 47 anticipation pairs, and it may be questionable whether these six pairs should be included in the anticipation group or not. However, in five out of six pairs, the parent's age at onset was assumed from the age at death, and then the actual difference in age at onset may be rather larger than the assumed difference because of the above mentioned reason.

Fourth, we excluded pairs involving the proband to eliminate bias towards apparent anticipation, but included pairs involving sibs of the proband or of the affected parent as the child, which may also tend to cause bias towards apparent anticipation. If they were excluded, our remaining data would be too few for analysis and more patients would be required. However, in large families with many patients ascertained, the patients in older generations who could produce several offspring should have a relatively later onset. Conversely, the patients in older generations who could produce no or a very small number of offspring because of early onset may be difficult to enter into the analysis. The missing data will cause bias towards apparent anticipation and cannot be compensated for, even though the additional children who would have been born to early onset patients in this study if they had had normal fertility were included. Thus, retrospective study of lethal disorders with reduced fertility harbours intrinsic ascertainment bias which is difficult to eliminate completely. Although collection of prospective data will be required, our study strongly suggests that anticipation in the transmission of Met30TTR FAP is a true biological phenomenon.

There was no significant difference in the age at onset between the probands of 15 families included in this study and the probands of type I FAP families not included. In comparison with these two groups, sporadic patients had a higher age at onset. This agrees with the previous suggestion that patients with Met30-TTR FAP whose parents were both unaffected had a later age at onset. ${ }^{27}$ If anticipation truly occurs, one may speculate that the disease is not expressed at all in some generations, and is expressed at a later age in only a few people in the next generation, and a further accelerated cascade of anticipation takes place until extinction of the disease gene owing to lack of fertility in early onset patients.

The first base (G) of codon 30 in the TTR gene is part of the $\mathrm{CpG}$ dinucleotide mutation hot spot sequence. ${ }^{28}$ Thus, it is very likely that the Met30-TTR mutation has recurred in various populations in the world and different type I FAP families with the same mutation have been generated. In fact, several independent origins of the Met30-TTR mutation have been proposed from haplotype analyses of the TTR gene. ${ }^{28-31}$ Yoshioka et $a l^{8}$ and our analysis (data not shown) showed that there were at least four separate origins of the mutation in Japan. The presence of several independent origins and the low prevalence of the disease implies rapid 
negative selection against the mutation. It seems that the most likely explanation for the rapid selection is the presence of anticipation.

Furthermore, anticipation in FAP is not only observed in the Met30-TTR type but also in the Pro55-TTR type. This type of FAP has been reported in West Virginia ${ }^{32}$ and Taiwan ${ }^{33}$ independently and showed early onset and rapid progression in both kindreds. In the West Virginia family, the age at onset decreased from the fourth to the second decade over four generations and finally the mutation became extinct owing to compromised reproductive potential. Similarly, the age at onset reduced from the fifth to the second decade over two generations and the mutation was lost in the Taiwanese family. Thus, Pro55-TTR can be seen as an extreme variant which shows anticipation and terminates its own transmission.

Considering that one base substitution in the TTR gene is responsible for development of the disease and cannot solely explain the anticipation phenomenon, Met30-TTR FAP is quite different from triplet repeat diseases. In three other autosomal dominant disorders, facioscapulohumeral muscular dystrophy, ${ }^{13} 14$ familial adenomatous polyposis, ${ }^{34}$ and polycystic kidney disease, ${ }^{11}{ }^{35}$ the anticipation phenomenon has also been described, although the known DNA abnormalities are stable during transmission. Thus, what mechanism can cause anticipation in Met30-TTR FAP or type I FAP?

No correlation between age at onset and the level of plasma Met30-TTR has been reported $^{536}$ and the clinical features common to symptomatic homozygotes are late onset and mild autonomic dysfunction in spite of high plasma Met30-TTR concentration. ${ }^{25}$ 37.39 Therefore, the age at onset may be determined not from regulating the expression of the Met30-TTR gene but by managing the local amyloid formation through some environmental/genetic factor(s), these unknown factor(s) also causing the anticipation phenomenon.

On one hand, changes of environmental factors such as "food culture", mentioned by Tashima et $a l,{ }^{20}$ may be important in influencing the age at onset. Yamamura ${ }^{40}$ reported that in a conventional environment transgenic mice carrying the human Met30-TTR gene had amyloid deposition within six months after birth, but in a specific pathogen free environment, genetically identical mice had no amyloid deposition by two years after birth. On the other hand, although between unilineal and bilineal pairs no significant difference was found for the differences in age at onset between parents and children, the possibility of influence of some genetic factor(s), for example abnormality of the SAP (serum amyloid $P$ component) gene, should not be dismissed. Our study showed that the affected children with maternal transmission had more pronounced anticipation than those with paternal transmission, especially when the children were sons. This phenomenon corresponds well with the reports of Portuguese $\mathrm{e}^{16-18}$ and Swedish ${ }^{19}$ families and this concordance does not seem to be a mere accident. This fact could adequately be explained by the existence of genetic factor(s) influencing the age at onset rather than by environmental factors. Although there is no information about whether methylation occurs for one parental allele, we cannot exclude unknown genetic factors, such as tandem repeat expansion or increasing copy number of abnormal mitochondrial DNA during transmission. A novel molecular mechanism which could explain the anticipation in TTR related FAP still requires to be clarified.

1 Costa PP, Figueira AS, Bravo FR. Amyloid fibril protein related to prealbumin in familial amyloidotic polyneuropathy. Proc Natl Acad Sci USA 1978;75:4499-503.

2 Benson MD, Uemichi T. Transthyretin amyloidosis. Amyloid: Int $\mathcal{f}$ Exp Clin Invest 1996;3:44-56.

3 Tawara S, Nakazato M, Kangawa K, Matsuo H, Araki S Identification of amyloid prealbumin in variant in familial Identification of amyloid prealbumin in variant in familial
amyloidotic polyneuropathy (Japanese type). Biochem amyloidotic polyneuropathy (Japane
Biophys Res Commun 1983;116:880-8.

4 Yamamoto K, Ikeda S, Yanagisawa N. Argentinian patients of European ancestory with familial amyloid polyneuropathy. Amyloid: Int $\mathcal{F}$ Exp Clin Invest 1994;1:90-3.

5 Sequeiros J, Saraiva MJM. Onset in the seventh decade and lack of symptoms in heterozygotes for the TTR ${ }^{\mathrm{Met} 30}$ mutation in hereditary amyloid neuropathy-type I (Portuguese, Andrade). Am $\mathcal{F}$ Med Genet 1987;27:345-57.

6 Kincaid JC, Wallace MR, Benson MD. Late-onset familal amyloid polyneuropathy in an American family of English origin. Neurology 1989;39:861-3.

7 Ridley RM, Frith CD, Crow TJ, Conneally PM. Anticipation in Huntington's disease is inherited through the male line but may originate in the female. 7 Med Genet 1988:25. 589-95.

8 Höweler CJ, Busch HFM, Geraedts JPM, Niermeijer MF Staal A. Anticipation in myotonic dystrophy: fact or fiction? Brain 1989;112: 779-97.

9 Orr HT, Chung MY, Banfi S, et al. Expansion of an unstable trinucleotide CAG repeat in spinocerebellar ataxia type 1 . Nat Genet 1993;4:221-6.

10 McInnis MG, McMahon FJ, Chase GA, Simpson SG, Ross CA, DePaulo JR Jr. Anticipation in bipolar affective disorder. Am ₹ Hum Genet 1993;53:385-90.

11 Fick GM, Johnson AM, Gabow PA. Is there evidence for anticipation in autosomal-dominant polycystic kidney disease? Kidney Int 1994;45:1153-62.

12 Horwitz M, Goode EL, Jarvik GP. Anticipation in familial leukemia. Am f Hum Genet 1996;59:990-8.

$13 \mathrm{Zatz}$ M, Marie SK, Passos-Bueno MR, et al. High proportion of new mutations and possible anticipation in Brazilian facioscapulohumeral muscular dystrophy families. Am f Hum Genet 1995;56:99-105.

14 Lunt PW, Jardine PE, Koch MC, et al. Correlation between fragment size at D4F104S1 and age at onset or at wheelchair use, with a possible generational effect, accounts for much phenotypic variation in 4q35facioscapulohumeral muscular dystrophy (FSHD). Hum Mol Genet 1995;4:951-8.

15 Sutherland GR, Richards RI. Simple tandem DNA repeats and human genetic disease. Proc Natl Acad Sci USA 1995; 92:3636-41.

16 Sousa A, Coelho T, Sequeiros J. Parental transmission and age-of-onset in familial amyloidotic polyneuropathy (Portuguese type). In: Natvig JB, Forre O, Husby G, et al, eds. tuguese type). In: Natvig JB, Forre O, Husby G, et al, eds. Amyloid

17 Sousa A, Coelho T, Lobato L, Sequeiros J. Anticipation of age-of-onset in familial amyloidotic polyneuropathy (Portuguese type). In: Natvig JB, Forre O, Husby G, et al, eds. Amyloid and amyloidosis 1990. Dordrecht: Kluwer, 1991: 694-7.

18 Sausa A, Coelho T, Lobato L, Sequeiros J. Parental transmission and anticipation of age of onset in FAP-I. Am f Hum Genet Suppl 1991;49:A2757.

19 Drugge U, Andersson R, Chizari F, et al. Familial amyloidotic polyneuropathy in Sweden: a pedigree analysis. F Med Genet 1993;30:388-92.

20 Tashima K, Ando Y, Tanaka Y, Uchino $M$, Ando $M$. Changes in the age of onset in patients with familial amyloidotic polyneuropathy type I Intern Med 1995;34: 748-50.

21 Penrose LS. The problem of anticipation in pedigrees of dystrophia myotonica. Ann Eugen 1948;14:125-32.

22 Araki S, Mawatari S, Ohta M, Nakajima A, Kuroiwa Y. Polyneuritic amyloidosis in a Japanese family. Arch Neurol Polyneuritic amyloid

23 Kito S, Itoga E, Kamiya K, Kishida T, Yamamura Y. Studies on familial amyloid polyneuropathy in Ogawa village, on familial amyloid polyneurop

24 Ikeda S, Hanyu N, Hongo M, et al. Hereditary generalized amyloidosis with polyneuropathy. Clinicopathological amyloidosis with polyneuropathy. Clinicopathological
study of 65 Japanese patients. Brain 1987;110:315-37.

25 Yoshinaga T, Nakazato M, Ikeda S, Ohnishi A. HomozygosYoshinaga T, Nakazato M, Ikeda S, Ohnishi A. Homozygos-
ity for the transthyretin-Met30 gene in three Japanese siblings with type I familial amyloidotic polyneuropathy. Neurology 1992;42:2045-7. 
26 Lunt PW, Compston DAS, Harper PS. Estimation of age dependent penetrance in facioscapulohumeral muscular
dystrophy by minimising ascertainment bias. $\mathcal{F}$ Med Genet 1989;26:755-60.

27 Coelho T, Sousa A, Lourenco E, Ramalheira J. A study of 159 Portuguese patients with familial amyloidotic polyneu159 Portuguese patients with familial amyloidotic polyneuropathy (FAP) whose

28 Yoshioka K, Furuya H, Sasaki H, Saraiva MJM, Costa PP, Sakaki Y. Haplotype analysis of familial amyloidotic polyneuropathy. Evidence for multiple origins of the $\mathrm{Val} \rightarrow$ Met mutation most common to the disease. Hum Genet 1989;82:9-13.

29 Ii S, Sommer SS. The high frequency of TTR $M^{30}$ in familial amyloidotic polyneuropathy is not due to a founder effect. Hum Mol Genet 1993;2:1303-5.

30 Waits RP, Uemichi T, Benson MD. Haplotype analysis of the transthyretin gene: evidence for multiple recurrence of the Met30 mutation in the caucasian population. Amyloid. Int f Exp Clin Invest 1995;2:114-18.

31 Almeida MR, Aoyama-Oishi N, Sakaki Y, et al. Haplotype analysis of common transthyretin mutations. Hum Genet 1995;96:350-4.

32 Jacobson DR, McFarlin DE, Kane I, Buxbaum IN. Transthyretin Pro55, a variant associated with early-onset, aggressive, diffuse amyloidosis with cardiac and neurologic involvement. Hum Genet 1992;89:353-6.

33 Yamamoto K, Hsu SP, Yoshida K, et al. Familial amyloid polyneuropathy in Taiwan: identification of transthyretin polyneuropathy in Tawan: identification of transth
variant $\left(\right.$ Leu $^{55} \rightarrow$ Pro). Muscle Nerve 1994;17:637-41.
34 Presciuttini S, Varesco L, Sala P, et al. Age of onset in familial adenomatous polyposis: heterogeneity within families
and among APC mutations. Ann Hum Genet 1994;58:331and 42.

35 European Polycystic Kidney Disease Consortium. The polycystic kidney disease 1 gene encodes a $14 \mathrm{~kb}$ transcrip and lies within a duplicated region on chromosome 16. Cell 1994;77:881-94.

36 Saraiva MJM, Costa PP, Goodman DWS. Biochemical marker in familial amyloidotic polyneuropathy, Portuguese type. Family studies on the transthyretin (prealbumin)methionine-30 variant. $\mathcal{F}$ Clin Invest 1985;76:2171-7.

37 Skare J, Yazici H, Erken E, et al. Homozygosity for the met30 transthyretin gene in a Turkish kindred with familial amyloidotic polyneuropathy. Hum Genet 1990;86:89-90.

38 Holmgren G, Bergström S, Drugge U, et al. Homozygosity Holmgren G, Bergström S, Drugge U, et al. Homozygosity
for the transthyretin-Met30-gene in seven individuals with familial amyloidosis with polyneuropathy detected by restriction enzyme analysis of amplified genomic DNA sequences. Clin Genet 1992;41:39-41.

39 Ikeda S, Nakano T, Yanagisawa N, Nakazato M, Tsukagosh . Asymptomatic homozygous gene carrier in a family with type I familial amyloid polyneuropathy. Eur Neurol 1992;32:308-13.

40 Yamamura K. Amyloid deposition in transgenic mouse model for familial amyloidotic polyneuropathy. In: Hirai S, eds. Annual report of the primary amyloidosis research eds. Annual report of the primary amyloidosis research
committee 1992. Tokyo:The Ministry of Health and Welfare of Japan, 1993:153-5. 